\title{
A short upstream promoter region mediates transcriptional regulation of the mouse doublecortin gene in differentiating neurons
}

\author{
Marie Piens 1,3, Marc Muller2, Morgan Bodson33, Gregory Baudouin 1,2 and Jean-Christophe Plumier*1
}

\begin{abstract}
Background: Doublecortin (Dcx), a MAP (Microtubule-Associated Protein), is transiently expressed in migrating and differentiating neurons and thereby characterizes neuronal precursors and neurogenesis in developing and adult neurogenesis. In addition, reduced Dcx expression during development has been related to appearance of brain pathologies. Here, we attempt to unveil the molecular mechanisms controlling Dcx gene expression by studying its transcriptional regulation during neuronal differentiation.

Results: To determine and analyze important regulatory sequences of the Dcx promoter, we studied a putative regulatory region upstream from the mouse Dcx coding region ( $p d c \times 2 \mathrm{~kb})$ and several deletions thereof. These different fragments were used in vitro and in vivo to drive reporter gene expression. We demonstrated, using transient expression experiments, that $p d c \times 2 \mathrm{~kb}$ is sufficient to control specific reporter gene expression in cerebellar cells and in the developing brain (E14.5). We determined the temporal profile of Dcx promoter activity during neuronal differentiation of mouse embryonic stem cells (mESC) and found that transcriptional activation of the Dcx gene varies along with neuronal differentiation of $\mathrm{mESC}$. Deletion experiments and sequence comparison of Dcx promoters across rodents, human and chicken revealed the importance of a highly conserved sequence in the proximal region of the promoter required for specific and strong expression in neuronal precursors and young neuronal cells. Further analyses revealed the presence in this short sequence of several conserved, putative transcription factor binding sites: LEF/TCF (Lymphoid Enhancer Factor/T-Cell Factor) which are effectors of the canonical Wnt pathway; HNF6/OC2 (Hepatocyte Nuclear Factor-6/Oncecut-2) members of the ONECUT family and NF-Y/CAAT (Nuclear Factor-Y).

Conclusions: Studies of Dcx gene regulatory sequences using native, deleted and mutated constructs suggest that fragments located upstream of the Dcx coding sequence are sufficient to induce specific Dcx expression in vitro: in heterogeneous differentiated neurons from mESC, in primary mouse cerebellar neurons (PND3) and in organotypic slice cultures. Furthermore, a region in the 3'-end region of the Dcx promoter is highly conserved across several species and exerts positive control on Dcx transcriptional activation. Together, these results indicate that the proximal 3'-end region of the mouse Dcx regulatory sequence is essential for Dcx gene expression during differentiation of neuronal precursors.
\end{abstract}

\section{Background}

The $D C X$ gene is located on the $\mathrm{X}$ chromosome (Xq22.3q23) and encodes a $40 \mathrm{kDa}$ phosphoprotein of 360 amino acids. The DCX protein is a microtubule-associated protein (MAP) that interacts with and stabilizes the microtubule cytoskeleton [1,2]. This gene is specifically and

* Correspondence: jc.plumier@ulg.ac.be

${ }^{1}$ Laboratory for Animal Physiology, Université de Liège, B-4000 Liège, SartTilman, Belgium

Full list of author information is available at the end of the article transiently expressed in proliferating neuronal progenitors and in post-mitotic neuronal precursors during embryonic development and in neurogenic regions of the adult brain [2-5]. $D C X$ expression occurs during corticogenesis and is absent during regenerative axonal growth, suggesting that DCX is a selective marker of cells committed to the neuronal lineage in both developing and adult brain [6,7]. One or more mutations in the $D C X$ gene cause X-Linked Subcortical Laminar Band Heterotopia (X-SCLH)/Lissencephaly (LIS) $[2,8]$. This developmental 
brain malformation syndrome is caused by abnormal neuronal migration leading to a profound cerebral cortical layer disorganization resulting in mental retardation and epilepsy.

Such alterations in cortical lamination observed in humans were not detected in mice with $D c x$ gene deletion; lamination defects were only observed in the hippocampus [9]. In contrast, RNA interference (RNAi)mediated knock-down of $D c x$ in rodents caused impairment in radial migration of cortical neurons $[10,11]$. Similarly, mice with mutations of both $D c x$ and Dclk (Doublecortin-like kinase gene, homolog of the Dcx gene) genes presented both disorganized neocortical lamination and severe cytoarchitectural defects of the hippocampus, suggesting redundant functions of $D c x$ and Dclk during neuronal migration [12-14].

Neuronal differentiation is a tightly orchestrated timeand location-dependent process in which many extracellular and intrinsic factors are involved [15-17]. Whereas the temporal and spatial $D c x$ expression patterns and Dcx post-translational regulations are well known, $D c x$ transcriptional regulation is poorly understood. However, to understand the mechanisms involved in neuronal differentiation during embryogenesis and more precisely in stages before neuronal determination, it is crucial to investigate the transcriptional gene control in action during neuronal differentiation. In view of the relevance of Dcx as a marker for neurogenesis and considering the importance of understanding $D c x$ gene regulation, we analyzed a putative regulatory region upstream of the mouse $D c x$ gene $(p d c x 2 \mathrm{~kb})$ and used it to drive reporter gene expression. We characterized the $D c x$ promoter activity at different time-points during neuronal differentiation of mESC (mouse embryonic stem cells) and we defined a small region as an element required to provide specific and strong expression in neuronal precursors and young neuronal cells.

\section{Results}

To study transcriptional regulation of the mouse doublecortin gene (Accession number NT_039718), we selected a $2 \mathrm{~kb}$-long fragment upstream of the transcription initiation site of the longest reported $D c x$ mRNA transcript (Accession number NM_001110222). This $2 \mathrm{~kb}$-long fragment $(p d c x 2 \mathrm{~kb})$ contained TATA and CAAT boxes and was cloned into promoterless reporter (eGFP or Luciferase) vectors for analysis (Figure 1a).

\section{Cell type-specific activity of the $\mathbf{2 k b}$-long Dcx promoter fragment}

We first wanted to determine whether $p d c x 2 \mathrm{~kb}$ was sufficient to induce transcriptional activity and to drive it specifically in cells expressing the endogenous $D c x$ gene, namely neuronal precursor cells. Two mouse cell types were used: cerebellar neurons from post-natal day 3 mice (PND3) in which endogenous Dcx expression has already been reported [18] and mouse embryonic stem (ESR1) cells.

Cell specificity of $p d c x 2 \mathrm{~kb}$ transcriptional activity was observed in both heterogeneous cell cultures by transient expression of the eGFP protein upon transfection with $p d c x 2 \mathrm{~kb}$-eGFP constructs (Figure $1 \mathrm{~b}$ ). In primary cerebellar cells, eGFP under the control of $p d c x 2 \mathrm{~kb}$ was detected only in cells expressing the endogenous $D c x$ gene and not in other cell types, such as GFAP-expressing astrocytes (Figure 1b: A-H). Control experiments using the widely active $p C M V$-eGFP construct revealed that eGFP fluorescence was detected indifferently in all cell types, neurons and glial cells alike. Both GFAP- and Dcxpositive cells were fluorescent (Figure 1b: I-P), showing that the transfection process was not cell-specific. Similarly, eGFP expression was only detected in ESR1 cells after neuronal differentiation and was limited to Dcxpositive or $\beta$ III-Tubulin-positive cells, confirming $p d c x 2 \mathrm{~kb}$ selectivity to Dcx-positive neuronal precursor cells in vitro (data not shown).

Ex vivo electroporation of embryonic mouse brains was also conducted to confirm cell selectivity of $p d c x 2 \mathrm{~kb}$ activity in a more physiological setting. pdcx2kb-eGFP was transfected in brains of E14.5-E15.5 mice, a specific time point of corticogenesis [19]. Dcx expression was observed in migrating cortical neurons originating from progenitor cells located near the ventricular proliferative zone. Following $p d c x 2 \mathrm{~kb}-\mathrm{eGFP}$ transfection, fluorescence was observed around the electroporation site in the proliferative zone of the cerebral cortex. Fluorescent cells displayed morphology similar to that of migrating neuronal precursors (Figure 1c). Moreover, all fluorescent cells also expressed Dcx. Taken together, these qualitative analyses show that the $2 \mathrm{~kb}$-long fragment upstream of the $D c x$ gene possesses regulatory sequences sufficient to mimic the activity of the endogenous $D c x$ gene in mouse embryos and to limit its activity to Dcx-positive neuronal precursors.

\section{Transcriptional activity of the Dcx promoter in differentiating ES cells}

To study more efficiently the transcriptional regulation of the mouse $D c x$ gene, we chose to use mouse embryonic stem (ESR1) cells: these cells are able to proliferate indefinitely in vitro while retaining pluripotency, and also to differentiate into a large variety of cell types in vitro. Hence, mouse ES cells can differentiate into neural precursors able to generate functional neurons [20], astrocytes and oligodendrocytes [21,22]. Using our protocol (see Material and Methods), induction of neuronal differentiation leads to a progressive change in ESR1 cell morphology to a characteristic cobblestone structure and, by 
b

a

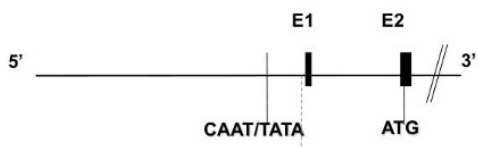

pdcx2kb

C

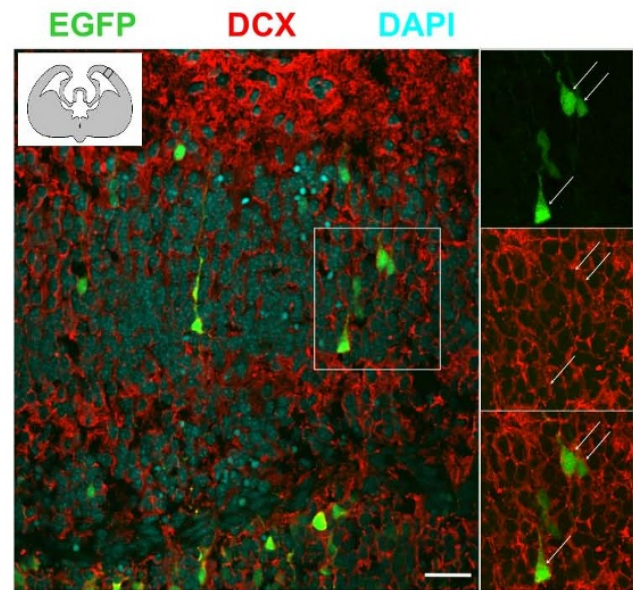

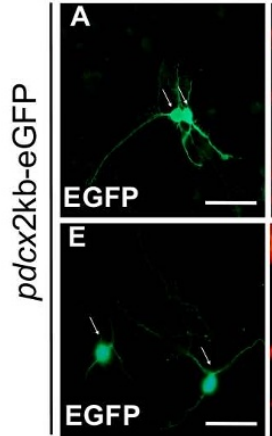
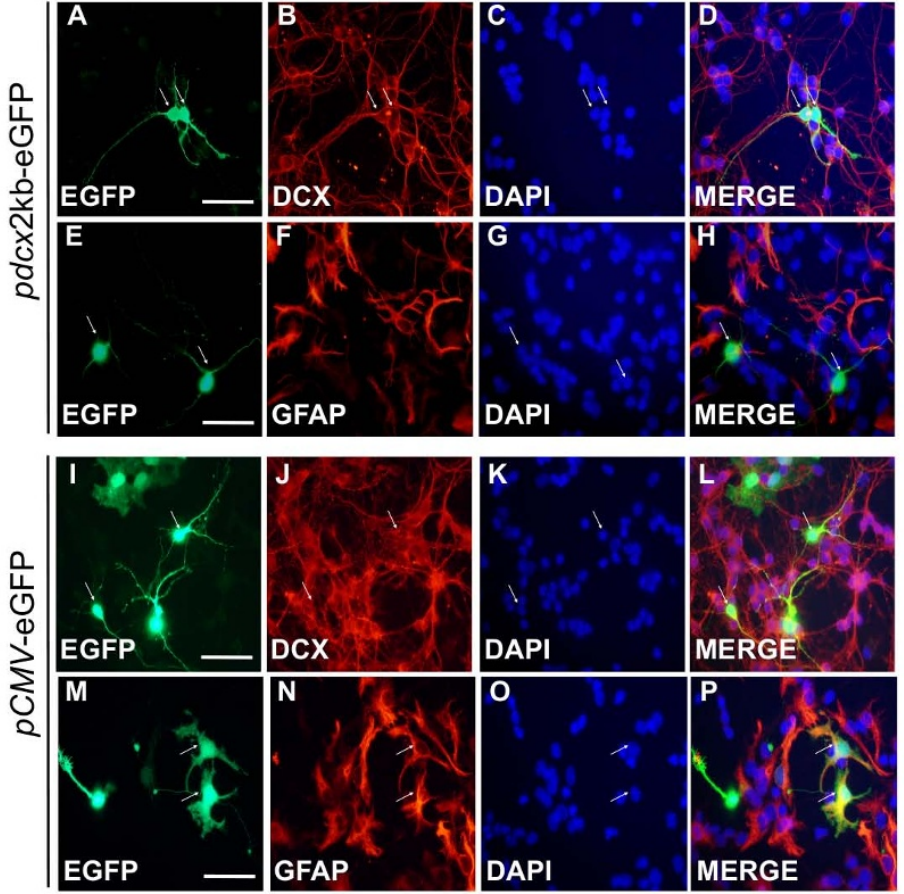

Figure 1 Neuronal lineage specificity of the doublecortin regulatory sequence ( $p d c x \mathbf{2 k b}$-eGFP). (a) Schematic representation of the mouse Dcx promoter construct for reporter gene expression: black boxes (E1 and E2) represent the first two exons of the Dcx gene: the localization of putative CAAT/TATA boxes and ATG start codon are shown (b) Cerebellar Granule neurons (CGN) extracted from PND3 mice were transiently transfected with pdcx2kb-eGFP (A-H) or pCMV-eGFP (I-P). After 72 hrs, expression of eGFP was analyzed using an inverted fluorescence microscope and compared with the neuronal cell-specific marker Dcx or astroglial cell-specific marker GFAP; DAPI was used as a nuclear counterstain. In cells transfected with the $p d c \times 2 k b$ plasmid, co-expression was observed between eGFP and Dcx (A-D). No expression overlap is observed between eGFP and GFAP (E-H). Cells transfected with pCMV-eGFP plasmid (I-P) present a strong eGFP expression with Dcx (I-L) and with GFAP (M-P). Scale bar equals $50 \mu \mathrm{m}$. (c) E15 embryonic mouse brains were electroporated with pdcx2kb-EGFP plasmid. After 4 days, organotypic slices were sectioned, immunostained with Dcx and counterstained with DAPI. Slices were analyzed by confocal microscopy. The insert shows the location of the microphotograph: eGFP, Dcx and their co-localization are presented. Scale bar equals $50 \mu \mathrm{m}$.

neuronal differentiation day 8 (DD8), ESR1 cells begin to form long cellular processes. From DD8/10 on, bipolar cells proliferate and form rosettes.

Dcx protein was detected at DD6 of ESR1 differentiation (Figure 2) and was still present in immature neuronal cells-derived from ESR1 cells at DD8 and DD18. Based on these observations and on the detection of Dcx mRNA at DD4, we decided to use ESR1 at DD6 for further analysis of the transcriptional activity of the mouse $D c x$ promoter.

To characterize relevant regions of $p d c x$, we dissected the $2 \mathrm{~kb}$-long fragment into shorter fragments of $1.2 \mathrm{~kb}, 1$ $\mathrm{kb}$ (obtained by PCR) and 249 bp (obtained by enzymatic restriction), and inserted them upstream of the luciferase reporter gene.

Comparison of the respective activities of all constructs (Figure 3a) in ESR1 cells at DD8 revealed a higher activity in cells transfected with $p d c x 2 \mathrm{~kb}$ than in control cells (figure $3 b)$. Transcriptional activities were also higher in cells transfected with shorter fragments $(p d c x 1 \mathrm{~kb}$ and $p d c x 249 \mathrm{bp}$ ) than with $p d c x 2 \mathrm{~kb}$ (Figure $3 \mathrm{~b})$. In contrast, the $1.2 \mathrm{~kb}$-long $p d c x$ fragment did not induce a transcriptional activity different from control, suggesting the pres-

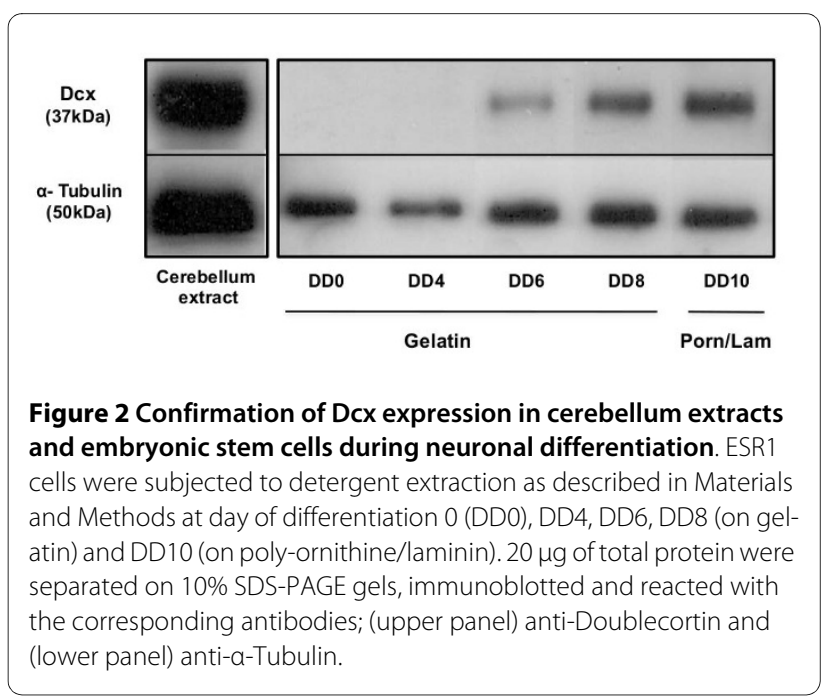


a

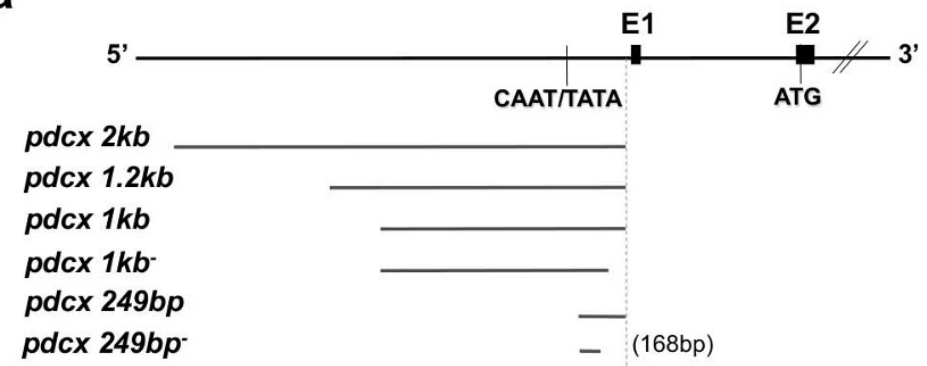

b

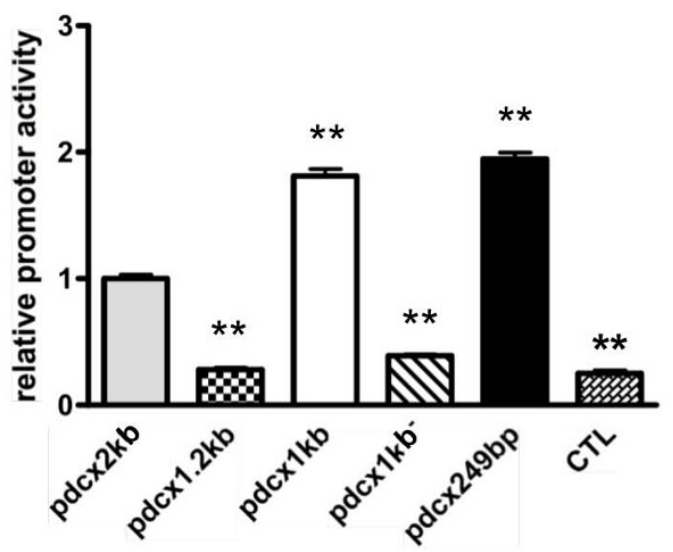

C

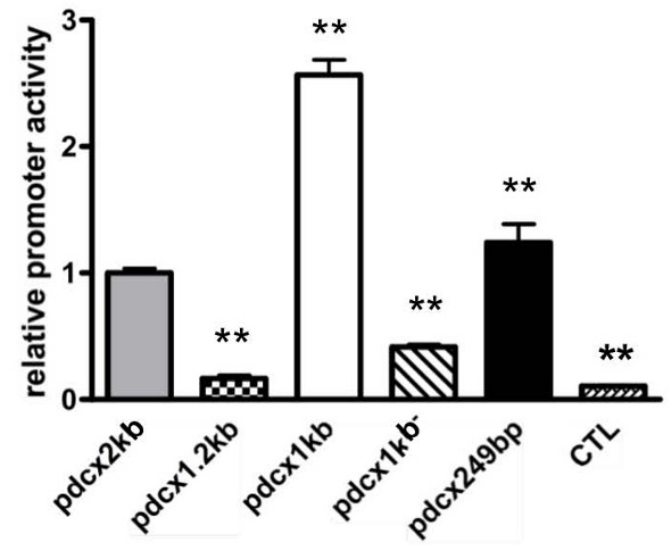

Figure 3 Transcriptional activity of the mouse Dcx upstream regulatory sequences in embryonic stem cells during neuronal differentiation and in cerebellar cells. (a) Schematic representation of the mouse Dex promoter constructs for reporter gene expression. Cells were co-transfected with Dcx promoter constructs or the basic vector (promoterless luciferase vector; $C T L$ ) and control pSV- $\beta$-Galactosidase vector. Luciferase activity (expressed in RLU), of each transfection was determined after 48 hours and normalized to the corresponding internal control, $\beta$-Galactosidase activity (OD at 420 nm). (b) ESR1 cells were transfected at DD6 program and (c) CGN were extracted from PND3 mice and transfected the same day. Each value represents the mean \pm SEM of at least three independent transfection experiments, each performed in triplicate. Asterisks mean significantly different from $p d c \times 2 \mathrm{~kb}$ values at $P<0.05\left(^{*}\right)$ or $P<0.01\left(^{* *}\right)$.

ence of a transcriptional repressor region in this $200 \mathrm{bp}$ fragment. In addition, deletion of $79 \mathrm{bp}$ at the 3'end of $p d c x 1 \mathrm{~kb}(p d c x 1 \mathrm{~kb}-)$ prevented the $p d c x 1 \mathrm{~kb}$-induced increase of activity. This last result suggested the presence of important regulatory domains at the 3'end of $p d c x$, especially in a 79bp-long fragment. Similar effects on the transcriptional activities of the different constructs were observed in PND3 cerebellar cells (Figure 3c), confirming the presence of similar regulatory control mechanisms in neuronal precursors from both origins (ESR1 cells and primary cerebellar cells). However, a discrepancy is observed between the relative activity of $p d c x 1 \mathrm{~kb}$ and $p d c x 249 \mathrm{bp}$ between both cell cultures (Figure $3 \mathrm{~b}$ and $3 \mathrm{c}$ ), maybe reflecting the fact that the target regulatory elements necessary for the $D c x$ gene expres- sion are different in two cell types. Indeed, it is quite possible that activators or inhibitor elements, located in $p d c x 1 \mathrm{~kb}$ and $p d c x 249 \mathrm{bp}$ respectively, are most needed during the differentiation of CGN compared to neuroblasts from ESC. At that stage (DD6), ESR1 cells are plated on gelatin-coated plates while cerebellar cells are plated on poly-ornithine substrate (necessary for cell adhesion) (see also below).

The same relative activities of the promoter fragments were maintained throughout the entire differentiation program in ESR1 cells (Figure 4). Indeed, when ESR1 cells were transfected every second day throughout the entire differentiation period and the luciferase activity measured 48 hours later, increasing levels of activities were observed along the process with a peak at the transfer 


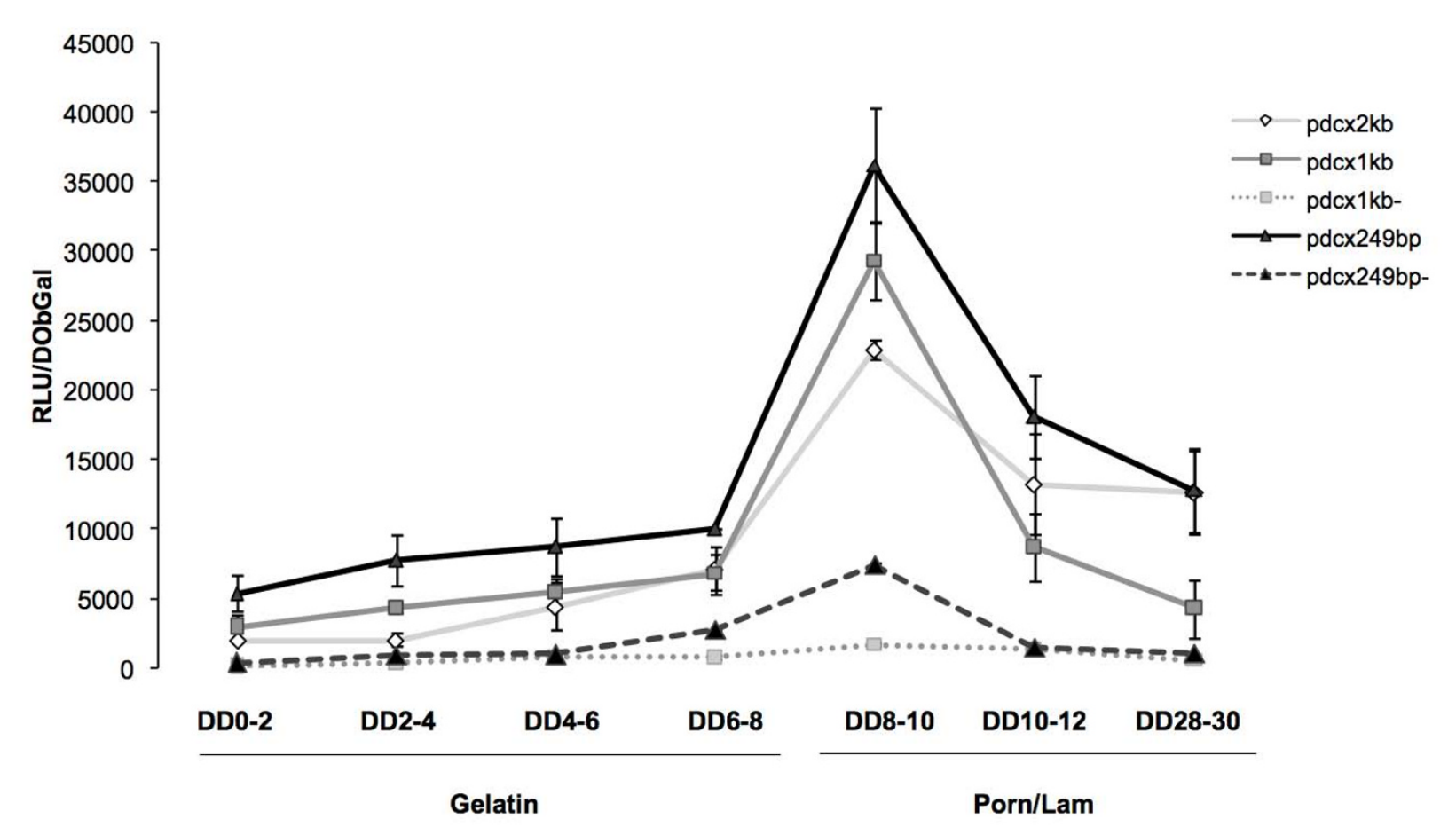

Figure 4 Transcriptional activity of the mouse $D c x$ upstream regulatory sequences in embryonic stem cells during differentiation. Every second day, cells were co-transfected with the indicated Dcx promoter construct or the promoterless control (CTL). Normalized luciferase activity corresponds to the luciferase activity (expressed in RLU) of each transfection (determined 48 hours later) normalized to the corresponding internal control, $\beta$-Galactosidase activity (expressed in OD at $420 \mathrm{~nm}$ ) (see materials and methods). Each value represents mean \pm SEM of at least three independent transfection experiments, each performed in triplicate.

onto poly-ornithine/lamin substrate for constructs $p d c x 2 \mathrm{~kb}, p d c x 1 \mathrm{~kb}$ and $p d c x 249 \mathrm{bp}$. The time-course studies confirmed the inhibition or the significant reduction of the transcriptional activity of $p d c x$ at all stages by deletion of $79 \mathrm{~b}$ at the $3^{\prime}$ end of the $p d c x$ sequences in constructs $p d c x 1 \mathrm{~kb}$ and $p d c x 249 \mathrm{bp} \quad\left(p d c \times 1 \mathrm{~kb}^{-}\right.$and $p d c x 249 \mathrm{bp}^{-}$, respectively). Finally, we also examined the cellular specificity of $p d c x 1 \mathrm{~kb}$ and $p d c x 249 \mathrm{bp}$ in differentiated ESR1 and PND3 cerebellar cells and confirmed that, similar to the $p d c x 2 \mathrm{~kb}$ construct (Figure $1 \mathrm{~b}$ ), both $p d c x 1 \mathrm{~kb}$ and $p d c x 249 \mathrm{bp}$ fragments restricted the expression of the eGFP reporter gene in Dcx-expressing cells (data not shown).

Transcription factors regulating the mouse Dcx promoter Comparative analyses were performed on the sequences of mouse, rat, human and chicken $2 \mathrm{~kb}$-long $D c x$ promoter fragments using the VISTA software (Figure 5). A high sequence similarity was found between mouse and rat $p d c x 2 \mathrm{~kb}$ sequences. Comparison between mouse and human sequences revealed that sequence conservation was not detected throughout the $2 \mathrm{~kb}$-long sequence, but was limited to a $\pm 500 \mathrm{bp}$ portion located at the $p d c x 2 \mathrm{~kb}$ 3 '-end. Similarly, sequence conservation between the mouse $p d c x 2 \mathrm{~kb}$ and the chicken $p d c x 2 \mathrm{~kb}$ was only observed in a $183 \mathrm{bp}$-long fragment located at the 3 '-end. In addition, the strongest sequence conservation between mouse, rat, human and chicken $p d c x 2 \mathrm{~kb}$ sequences was

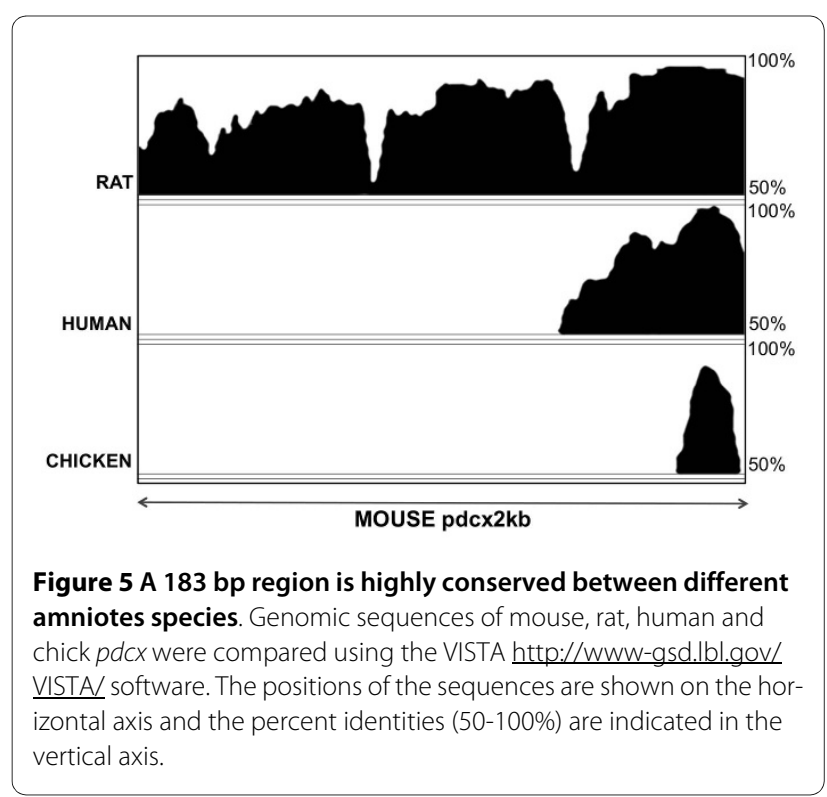


detected within this 183bp-long fragment (Figure 5). Further analysis, using the MatInspector software, revealed that many putative binding sites for members of several transcription factor families known to participate in neuronal differentiation/migration such as NEUROD, NEUROG, BRN, PAX, HOX, SOX and DLX are present in the 249bp-, 1kb-, 2kb-long $D c x$ promoter fragments (Additional file 1: Table S1). In particular, this analysis revealed four conserved consensus binding sites for known transcription factors in the 79b-long fragment located at the 3 'end of the $D c x$ promoter (Figure 6): two perfect consensus sites for NF-Y/CAAT, one perfect site for LEF/TCF which are effectors of the canonical Wnt pathway and one imperfect site for HNF6/OC2 (75\% conserved relative to consensus), members of the ONECUT family [2325].

\section{pdcx2kb}

2001 TTATAATTAATCTTAGTAGTTTAACACTTGATTTAATCGATCAGTCATAT

1951 TAGCTATAATCCAAGCTTTGTGGTCTTTCATTTCCATTTTACATATTTTG 1901 GCAATTTAATAGAAAAATTTTTTGGGCTTTTTCTTGAAATGTATAGATGA 1851 CGTTCGGGGAAGACTGATATTCTTATCGCCGCACATCTTTGAGTCTTACT 1801 GTGAGCATGGGCTGAATCCCTTTCTCCCCATAACCAGTAGCTGCCAGTAT 1751 СTCCTTAGCACGCTGAAGCTCCTTACCCATCCACAATGGAATGCTGAGGT 1701 ACTGGTCTTATTCAATTAATAACAgCTACTATGAGTTCATGATCGCTGTG 1651 TCCAGAAGAACCCCCCCCTCCСACTTTGCTCCAGCTCTTACATTCTTTCA 1601 TTTCCTTCTTCAATGATGAGTCCTGAACCTAGGAGAGGATGATAAAATGT 1551 CCCACTTAAGGCTGAGCGAGTGTTCAACAGCCACTCATTCTCAGCACATG 1501 GACCAGGTATGAGTCTCTTTGTTAACTGTTTACAGCTGCAAACAGACTTT 1451 TCTTTGACCATGACTGAGAAACCCTAACCTTTCGCTAATCTTTAATCTAT 1401 TAGgTAGAAACACAAACATTTAGAAGGTAGTTTGACACCATGTCTATTGA 1351 GCCAAACAACAGTAATCAGTTTCTCCCTAGAGCCTATGACCTCCAAAGAC 1301 ATAGTAGCTTTTAACCAGTTGTATAGAACCAGAAGATTCCACTCTACGGA 1251 CTAGACCTCAATTCCCAATCTTTAAAACACACTTCCCTTCTTAGGTGCTG 1201 CTTTCCCTTTTTTGATGTCTACACACACACACACACACACACACACACAC

1151 ACACACACACACACACACACACTATAAGCTAAAGTCCCATATGAAAGAAA 1101 GAAAATAAATCCTTTTGTCTCTCTCAGCCTCGGATACTTCACTCAGTATA 1051 TCATTTTCGGTTCCACACAATTTCTTGCAAATCTCATAATTTCACATTTT 1001 ACTGATGGGTGATTAAAATCATGCATATATCTTGCATTTTCATTACCCAT

\section{Expression of putative transcription factors during neuronal differentiation of $\mathrm{mESC}$}

To investigate which of these transcription factors, present in the $79 \mathrm{bp}$ fragment and potentially involved in $D c x$ gene regulation, are expressed during neuronal differentiation of ESR1 cells, the levels of mRNA coding for Dcx and for each factor (Lef, Tcf1, Tcf3 and Tcf4, Hnf6 and $O c 2, N f-y a, N f-y b$ and $N f-y c$ ) were measured at different time-points during neuronal differentiation (Figure 7).

The abundance of each transcript at each stage was calculated relative to the Gapdh housekeeping gene mRNA, based on published results [26-28]. The observed pattern of $D c x$ transcript expression is consistent with that of Dcx protein synthesis during neuronal differentiation of ESR1 cells and with the observed transcriptional activity of the $D c x$ promoter (see above). No $D c x$ transcript was detected in undifferentiated ESR1 cells. Levels of $D c x$
951 TCATCTGTTAACAGACATCTGGGCTGTTTCTATTTTCTGGCTTTTGTGAA

901 TAGAGCAGCCATAAACACAGATATGCAAGTGTCTCTATGGTAGGTTATAG

851 TCTCCTTTGGGTATATGCCCAGGAGTGGGAAGGTGAAACATTAACCAATG

801 TTTTACATCAGTCTAAAATGTTTTGGAGTCATGCTGGGCCTAGAGACCTA

751 AGTGCTGGCAAATTCTAGTAGCCAAGAAGCAGAACAGAGGCTGAAAATTT

701 TCAGCAAATGAGAGGTCAGCCTGGGCTACACAGCGAGTTCCAGAACAACT

651 ATCACTATAAAGCTGGACCCTGACTCGATAAAACAACTGAACAAAAACTT

601 GGAGAAGTGCCACTTTTCAATTCCAGCCTTCATGATTCCTGCAACTATTT

551 TCCCGTGTACTGTCAATTTACTATTCCTGCTGACTTCGTTTAAAAAACAA

501 CCAGTGTTGGATGCATGAGCCGAAATGTTAAAAAATTTACATATTTTTTA

451 TTTTCTTTGAAGAAGATAAAAAGAGGAGATCTGTAATTTCTAAGAAACTT

401 GATTTGGCCTGCTGAGTCCAGCCACTAGGCAGAAGGTTTTAGCCAAGTAA

351 AATTGCCAATTTTCTAAGAGAAAGGGCTAGCACATTGCTCATTAGAGCAT

301 TCTGAGCTTGCCTGTGCAATCTTTTTTTTCCTACCCTGCAATTTCCTGTG

251 CGTTATAAACGAAACCTTTCTAGCTGTTAATGCAGGCTGTGAATTGAAGA

HindIII

201 AAAAAAAAGCATGTAATTAATCATAGGAGGTTGGGGGTGTTCGCTAAGCT

151 TCAGTTACAGGGGAGAAGCTGGACAAGGCACTAGGACCTAGAAGGCAACT

101 ATCCACCCTGGCAGGAATTTCTTGCTTGGAGCTCAGACAA CAAAGGCATA

1 GAGAGA

AATCGAATTCCCGCGGCCGCCATGGCGGCCGGGAGCATGCGACGTCGGGC

CCGGGATCCACCGGTCGCCACCATG $\longrightarrow$ REPORTER GENE

Figure 6 Nucleotide sequence of the mouse $\boldsymbol{D} c x$ gene regulatory sequence. The fragments corresponding to $p d c x 2 \mathrm{~kb}, p d c \times 1.2 \mathrm{~kb}, p d c \times 1 \mathrm{~kb}$ (obtained by PCR) and $p d c \times 249 \mathrm{bp}$ (obtained by enzymatic restriction) are represented. Sequence of $79 \mathrm{bp} \Delta(-1820-1741$ from ATG of Dcx gene) is indicated in bold and putative binding sites for transcription factors NF-Y, HNF6 and LEF/TCF surrounded by boxes. Reporter gene translation Initiation Site is highlighted in bolt. 

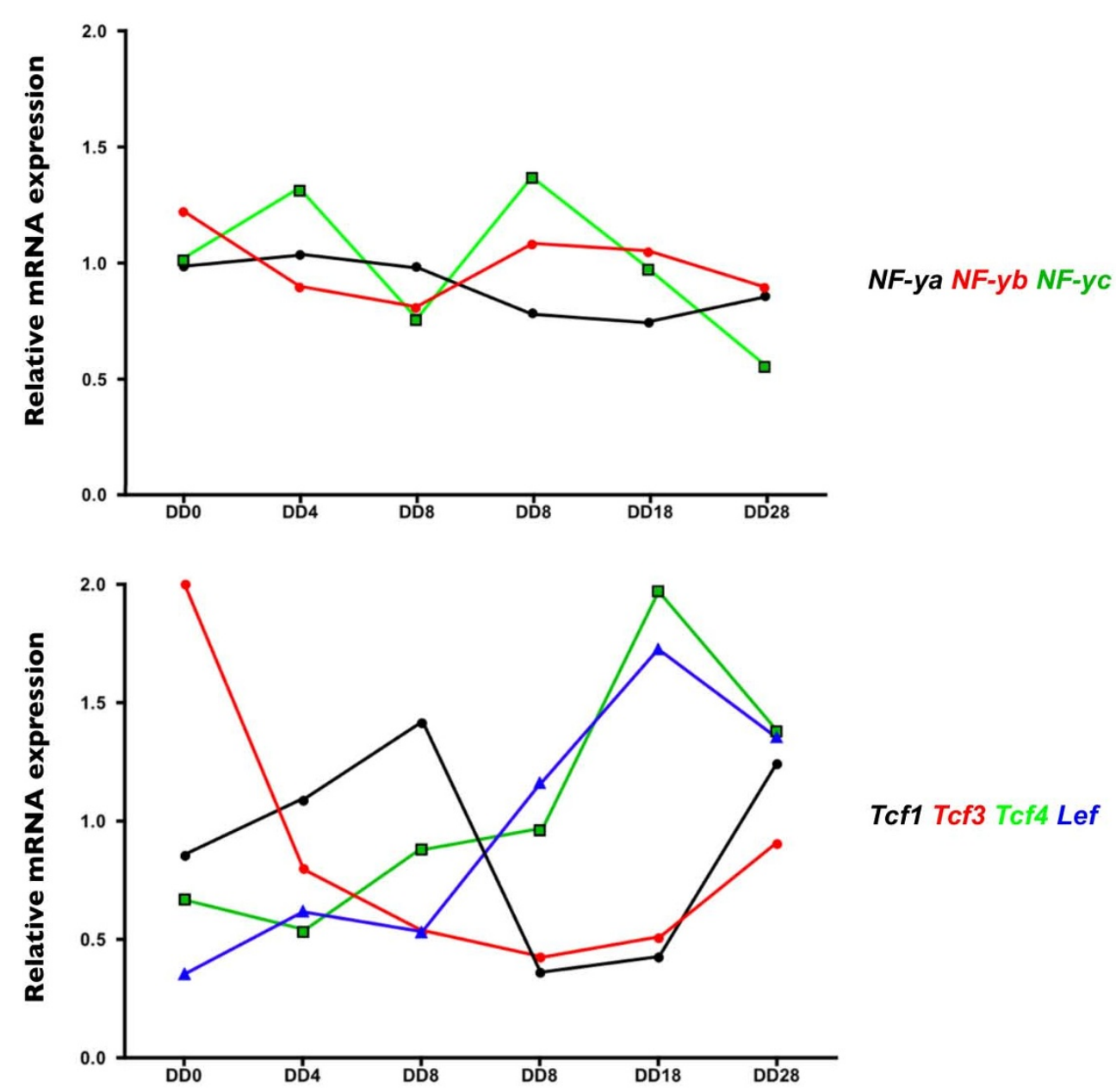

Tcf1 Tcf3 Tcf4 Lef

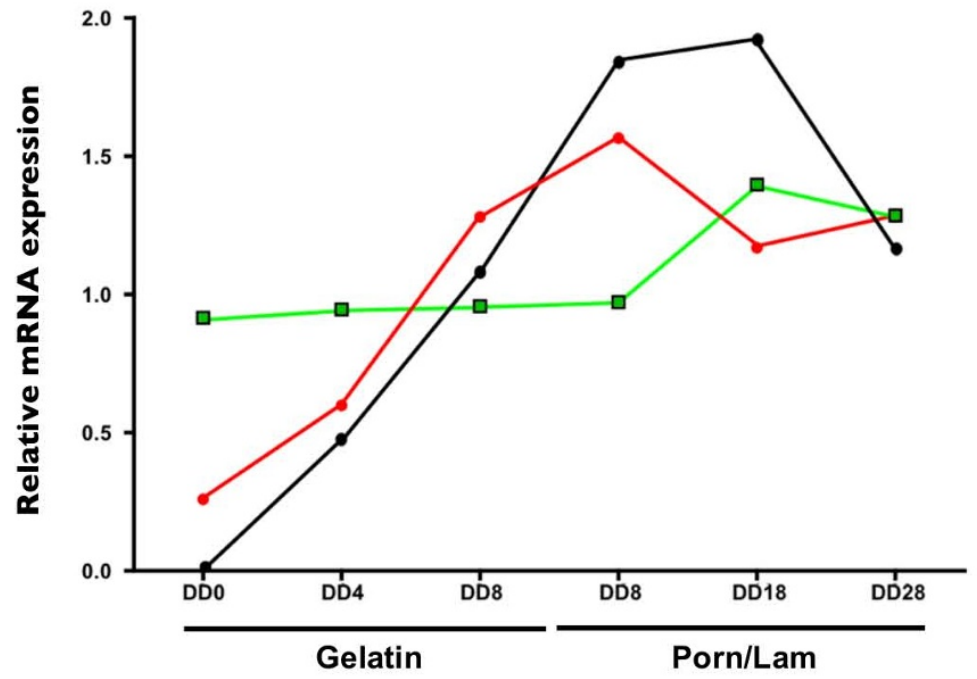

Figure 7 Expression of transcription factors predicted to bind the $D \boldsymbol{c x}$ regulatory sequence in the 3 '-end region. The relative abundance of mRNA coding for Dcx, Lef, Tcf1, Tcf3, Tcf4, Hnf6, Oc2 and Nf-ya, Nf-yb and Nf-yc were determined by semi-quantitative PCR at DD0, DD4 and DD8 on gelatin and at day of differentiation DD8, DD18 and DD28 on poly-ornithine/laminin. Gapdh was used as internal control. 
transcripts progressively increased to reach a maximum at DD18 followed by a reduction at DD28. Each transcription factor transcript was detected in ESR1 cells. The temporal profile of Lef, Hnf6 and Tcf4 transcription factors presented patterns of expression similar to that of $D c x$, suggesting that expression of these transcription factors is also dependent on neuronal differentiating time. Their levels were relatively low during the early phase of ESR1 cell differentiation (DD0-8), progressively increased during the late phase of the differentiation program to peak at DD18 when $D c x$ transcript levels were maximum. In contrast, $N f-y a, N f-y b, N f-y c$ and $O c 2$ transcripts displayed relatively constant steady state levels, with little variation during the entire differentiation program. The relative amounts of $T c f 1$ and $T c f 3$, seem to depend on the differentiation process, with $T c f 3$ decreasing during differentiation [29] and $T c f 1$ being apparently sensitive to the culture matrix substrate.

Since mRNA for each transcription factor was present in ESR1 cells and since no transcription factor could be discarded on the sole basis of the temporal expression profile of its transcript, selective mutagenesis experiments were undertaken.

To determine the relative importance of each DNA binding site present in the 79bp-long $p d c x$-luciferase fragment, we individually altered each putative binding site for LEF/TCF, HNF6/OC2 or NF-Y/CAAT in the Dcx promoter using site-directed mutagenesis to generate $p d c x 249 \mathrm{bp} / L e f^{*}, p d c x 249 \mathrm{bp} / H n f 6^{*}$ and $p d c x 249 \mathrm{bp} / N f-y^{*}$ (Figure 8). Then we compared the luciferase activities induced by each construct to that of $p d c x 249 \mathrm{bp}$ by transient expression experiments in ESR1 cells at three stages of neuronal differentiation. At the beginning of the differentiation program (DD2), mutation of the NF-Y or HNF6 binding sites did not affect $p d c x 249 \mathrm{bp}$ activity (Figure 8a). In contrast, mutation of the LEF/TCF site completely inhibited $p d c x 249 \mathrm{bp}$ activity. Such inhibition was not detected in ESR1 cells at DD8 (Figure 8b). At that stage, the relative activity of every mutated $p d c x 249 \mathrm{~b}$ was below that of the wild type $p d c x 249 \mathrm{bp}$ but higher than that of the 79bp-truncated $p d c x 249 \mathrm{bp}$. Finally, at DD20, when many ESR1 cells expressed the $D c x$ gene and displayed a neuronal phenotype, mutation of any of the four binding sites reduced the activity of $p d c x 249 \mathrm{bp}$ to that of the 79bp-truncated $p d c x 249 \mathrm{bp}$ (Figure 8c). Similar results were found using $p d c x 1 \mathrm{~kb}$ (data not shown) and in PND3 cerebellar cells (Figure 8d). Simultaneous mutation of all three binding sites was also performed ( $p d c x 249 \mathrm{bp} /$ Lef $^{*} /$ $\left.H n f 6 * / N f-y^{*}\right)$. Transfection experiments revealed that the transcriptional activation of p $d c x 249 \mathrm{bp}$ mutated for LEF, HNF6 and NF-Y binding sites is similar to the constructs with any one mutated site (Additional file 2: Figure S1) at all stages, suggesting that an additional, not yet identified factor is responsible for the observed residual activity at
DD8. Altogether, these results demonstrate first of all the importance of LEF/TCF, HNF6/OC2 or NF-Y/CAAT DNA binding sites for $D c x$ promoter activity at various stages of neuronal differentiation and that the corresponding factors are part of the regulatory mechanisms controlling $D c x$ promoter activity. However, these transcription factors are not sufficient to induce full transcriptional activation of the $D c x$ gene. In addition, the results obtained with the LEF/TCF binding site reveal that this binding site could be more specifically involved in activating $p d c x$ at early stages of neuronal differentiation of ESR1 cells.

\section{Discussion}

This present study shows that $249 \mathrm{bp}-, 1 \mathrm{~kb}-, 2 \mathrm{~kb}-$ long DNA fragments located upstream of the $D c x$ coding sequence, are sufficient for in vitro specific $D c x$ expression: in heterogeneous differentiated neurons from mouse embryonic stem (ESR1) cells, in primary mouse cerebellar neurons (PND3) and in organotypic slice cultures. The regulatory activity of all three constructs, visualized by eGFP expression, overlapped endogenous expression of Dcx or BIII-Tubulin (data not shown) in immature neuronal cells. In addition, no eGFP expression was observed in non-neuronal cells. These results strongly suggest that the fragments isolated here are sufficient for specific neuronal expression in differentiating neural cells.

During our analysis of transcriptional activities of the deletion constructs, we observed a very weak activity of the $1.2 \mathrm{~kb}$ fragment relative to the $1 \mathrm{~kb}$ construct, suggesting that the $0.2 \mathrm{~kb}$ sequence upstream from $p d c x 1 \mathrm{~kb}$ could contain transcriptional repressor elements. To determine the regulatory element(s) susceptible to participate in transcriptional repression of $D c x$ expression, we analyzed this sequence with the MatInspector software http://www.genomatix.de, but no unique repressor element was identified. However, this $0.2 \mathrm{~kb}$ sequence holds a short tandem repeat (STR) of twenty-five CA repeats (Figure 6), that could act as positive or negative regulator of gene expression. Short tandem repeats have been identified and are widespread in coding and non-coding regions of eukaryotic genomes from yeast to humans $[30,31]$. CA repeats are also potential Z-DNA-forming sequences that could affect gene expression. Indeed, STRs were shown to activate or repress gene expression depending on the length of the repeats [32,33]. This potential repressive element was not further investigated in this work, but it certainly deserves further attention also in the context of $D c x$-related disease.

Dcx is expressed in differentiating/migrating immature neurons of embryonic and adult CNS and PNS. Moreover, Dcx presents a maximum expression during corticogenesis (E14-E18 in mouse) and neurogenesis [18,34]. 


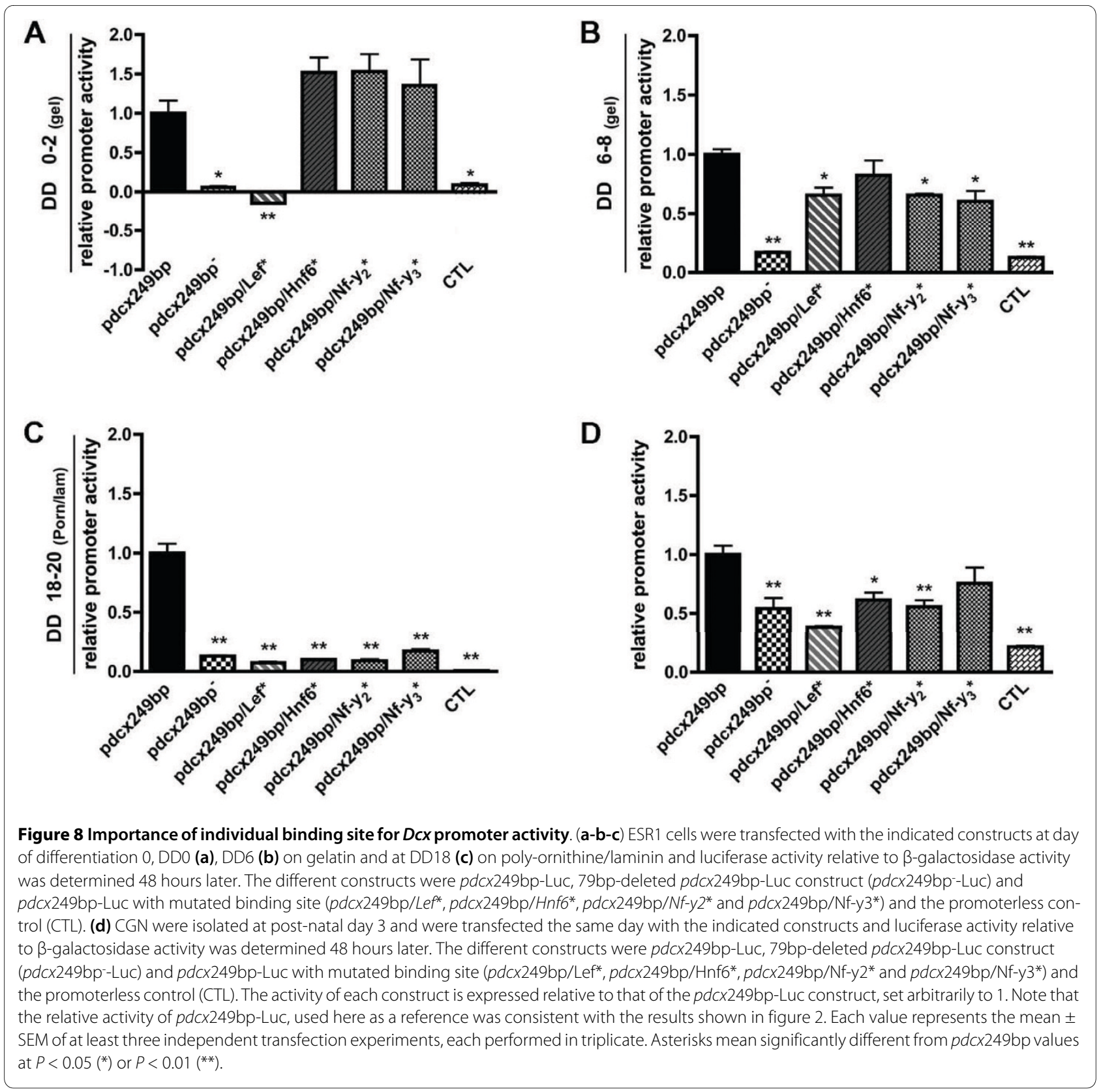

Using a mouse ESC model of neuronal differentiation, we demonstrated that the transcriptional activity of the $D c x$ promoter increased during the differentiation program, with a maximum activity shortly after the cells were plated on poly-ornithine/laminin substrates [35]. Both of these extracellular matrix (ECM) components were shown to promote the active extension of neuronal cell protrusions as well as their maturation [36-38]. In the present study, we further show that ECM components also promote expression of the endogenous Dcx protein, in a pattern fully consistent with the transcriptional activity of the identified promoter region during the same differentiation process. This interesting observation suggests that it is possible to reproduce the $D c x$ expression profile in an in vitro cell culture model and use it to better study the mechanisms involved in neuronal differentiation of ESC $[1,2,5,34,39,40]$.

DNA binding sites for several transcription factors (E2F, NeuroD1, Brn2,..), known to participate to neuronal and migration processes were pointed out by bioinformatics analyses of the $2 \mathrm{~kb}$-long DNA regulatory sequence of the mouse $D c x$ gene. Most of the transcription factor binding sites present on the mouse DNA regulatory sequence were also detected on a $3.5-\mathrm{kb}$ DNA fragment upstream of the translation start codon of the human $D C X$ gene [41]. This human sequence included a 
sequence homologous to the sequence used in the present study and the first exon of the human $D C X$ gene. Furthermore, deletion experiments revealed the presence of critical regulatory sequences in a short fragment showing high sequence homology across species. Within this sequence, three relevant consensus binding sites were detected. Each transcription factor selected in the $p d c x$ 3'-end (Lef/Tcf, Hnf6/Oc2, Nf-y/CAAT) is known to play a role, in a time-dependent manner, in the neuronal differentiation program. Mutational analysis revealed the outstanding importance of the LEF/TCF potential binding site for activation in early stages of the differentiation process, while at later stages the activity seems to be evenly distributed among all the binding sites. Simultaneous mutation of all three binding sites located in the 79 bp did not abolish the transcriptional activity of the $D c x$ promoter, implying that $D c x$ residual expression could be caused by a not yet discovered transcription factor located in the $79 \mathrm{bp}$ region. Interestingly, the three transcription factors whose expression pattern during neuronal differentiation correlated best with $D c x$ promoter activity were Hnf6, Tcf4 and Lef. The latter are mediators in the canonical Wnt pathway that participates in many developmental processes in vivo and in vitro [42-46]. The involvement of $L e f$ in the first steps of $D c x$ gene activation is consistent with the observations that some effectors of the Wnt canonical pathway contribute to neuronal differentiation of pluripotent cells, at least at specific stages $[45,47]$. Hirabayashi and co-workers proposed that the Wnt signaling pathway directs neuronal differentiation in the developing mouse neocortex [48]. They showed that activated $\beta$-catenin induced differentiation of Neural Precursor Cells (NPCs) at specific stages, whereas other studies suggested that Wnt signaling promoted NPC selfrenewal [49]. LEF/TCF and the other identified transcription factor complexes also play a role at later stages of the neuronal differentiation of ESC.

In silico analysis of the $D c x$ promoter, combined with mutagenesis experiments and RT-PCR analyses singled out the interesting ONECUT factors. First, a putative binding element for HNF6/OC2 was identified (75\% conserved relative to consensus) in the $79 \mathrm{bp}$ sequence (four on the total sequence of $\mathrm{p} d c x 2 \mathrm{~kb}$ ); second, the Hnf6 mRNA expression profile matched that of $D c x$ and third, mutation of the HNF6 binding site abolished $D c x$ promoter activity. Together, these results suggest that ONECUT factors could be involved in $D c x$ regulation. Hnf6 and other ONECUT factors have been detected in mouse $[23,24]$, the zebrafish [50] and also in drosophila and ascidia developing nervous system [51,52]. All this information suggests that HNF6 and other members of the ONECUT family could play a role during neuronal differentiation and possibly in $D c x$ regulation. Further experi- ments are currently underway in order to clarify ONECUT action on Dcx expression

Data presented in this study suggest that the maturation state of differentiating neuroblasts could be characterized by a specific transcriptional activity of the $D c x$ gene. Some data suggest that the mouse embryonic brain (E14) contains two distinct populations of Dcx-positive cells, according to their Dcx expression levels [3]. In these Dcx-positive cells, isolated by flow cytometry from the brains of transgenic mice expressing $p d c x$-eGFP in embryonic, early postnatal and adult animals, cells with a low level of Dcx expression (Dcx $\left.{ }^{\text {low}}\right)$ were multipotent as shown by their expression of nestin. On the other hand, Dcxigh cells showed an established neuronal specification, characterized by their expression of neuronal markers like BIII-Tubulin or MAP2. These results support the idea that all $\mathrm{Dcx}^{+}$neuronal precursors do not have the same potential to differentiate. In this study, neuronal cells obtained from differentiation of ESC or primary cell cultures from brain embryos form a heterogeneous neuronal cell population. In this context, it is not surprising that $\mathrm{Dcx}^{+}$cells, obtained from ESC differentiation, display different levels of $D c x$ promoter activity. This most probably reflects an asynchrony of differentiating ESC stages in the same cell culture.

\section{Conclusions}

The present work provides a molecular and cellular study of regulatory sequences ( $p d c x 2 \mathrm{~kb}, p d c x 1 \mathrm{~kb}, p d c x 249 \mathrm{bp}$ ), sufficient to promote specific neuronal expression of mouse $D c x$ in neuroblasts. We show here that $D c x$ expression is abolished when a specific region in the 3'end of the promoter is lacking. In addition transcription factor binding sites (LEF/TCF, HNF6/OC2 and NF-Y/ CAAT) localized in this promoter region seem to act in a time-dependent fashion on the transcriptional activity of the $D c x$ gene during neuronal differentiation of ESC. Future experiments on these short regulatory sequences will help to understand the transcriptional regulation of $D c x$ gene expression and, maybe to isolate precursors at defined stages of neuronal differentiation based on their Dcx expression.

\section{Methods}

\section{Animals}

All experimental procedures on animals were carried out according to the European Communities Council Directive (86/609/EEC) for care and use of Laboratory animals. The experimental protocols were reviewed and approved by the institutional Animal Care Committee.

\section{Materials}

ES cell culture medium ingredients (DMEM/F12, Neurobasal medium, B27 supplement, Bovine Serum Albu- 
min and L-glutamine) were obtained from InvitrogenGibco (Merelbeke, Belgium); BMP4 (Bone Morphogenic Protein-4) was obtained from R\&D Systems (Abingdon, United Kingdom); apo-transferrin, progesterone, insulin, putrescine, sodium selenite, laminin, poly-ornithine and all chemicals were obtained from Sigma-Aldrich (St. Louis, MO, USA) unless specified otherwise and ESGRO (LIF, Leukemia Inhibitory Factor) was from Chemicon International (Temicula, CA, USA) unless specified otherwise.

\section{ESC Culture - Monoculture Differentiation and Transfection} ESR1 cells were maintained without feeder cells in serum-free culture medium. ESC were plated onto $0.1 \%$ gelatin-coated plates in N2B27 medium (as described by Ying et al., 2003 [28]) supplemented with ESGRO (LIF) $10^{3}$ Units and BMP4 $10 \mathrm{ng} / \mathrm{ml}$ and incubated at $37^{\circ} \mathrm{C}$ in $5 \% \mathrm{CO}_{2}$. The medium was renewed every day. Cells were plated every 3 days using a dissociation solution (trypsin $0.05 \%$, chicken serum 1\%, EDTA $0.53 \mathrm{mM}$ ). To start monolayer differentiation, corresponding to DD0, undifferentiated cells were dissociated and plated onto $0.1 \%$ gelatin-coated plates at $10^{4} \mathrm{cells} / \mathrm{cm}^{2}$ in N2B27 medium supplemented with ESGRO ${ }^{\circ}$ (LIF) $10^{3}$ Units. The medium (non-supplemented N2B27) was changed every other day during 8 days, until DD8. Then, at DD8, cells were dissociated and plated on poly-ornithine $(100 \mu \mathrm{g} / \mathrm{ml})$ and laminin $(0.5 \mu \mathrm{g} / \mathrm{ml})$-coated plates. The medium was changed $2 \mathrm{~h}$ and $24 \mathrm{~h}$ after plating and every 2 days until 20 days of differentiation on porn/lam substrate, corresponding to DD28. ESR1 cells can differentiate into neural precursors, which could generate functional neurons [53], astrocytes, and oligodendrocytes [21,22].

Transient transfection experiments were performed using FuGene-6 (Roche Applied Science, Roche, Mannheim, Germany) as described by the manufacturer. eGFP expression was checked $24 \mathrm{~h}, 48 \mathrm{~h}$ and $72 \mathrm{~h}$ after transfection or luciferase/ $\beta$-galactosidase activity ratios were determined 48 hours after transfection. The luciferase activity was measured according to the Luciferase Assay System (from Promega, Leiden, The Netherlands) and is expressed in RLU (Relative Light Units). The $\beta$-galactosidase activity was determined by reacting $40 \mu \mathrm{l}$ of lysate with $40 \mu \mathrm{l}$ of $\beta$-galactosidase substrate containing ONPG (o-nitrophenyl-D-galactopyranoside) and the absorbance was measured at $420 \mathrm{~nm}$.

\section{Cerebellar Granule Neuron (CGN) Culture and Transfection}

Primary cultures of CGNs were obtained from post-natal day 3 (PND3) 129/sv mice. Isolated cerebella were stripped off meninges in DPBS (Dulbecco's PhosphateBuffered Saline) (Invitrogen-Gibco) supplemented with glucose $(0.45 \%)$, minced, and treated with dissociation solution ( $0.25 \%$ trypsin, $0.01 \%$ DNase) for $25 \mathrm{~min}$ at $37^{\circ} \mathrm{C}$.
Cell dissociation was stopped by adding $0.5 \mathrm{ml}$ of FBS (Fetal Bovine Serum) to the dissociation solution. Granule cells were then mechanically dissociated by two successive triturations and sedimentation steps in complete medium (DMEM, $25 \mathrm{mM} \mathrm{KCl}, 96 \mathrm{mM} \mathrm{NaCl}, 5 \mu \mathrm{M}$ insulin, $2 \mathrm{mM}$ glutamine, $1.5 \%$ glucose $30 \%, 1 \%$ sodium pyruvate, $5 \%$ heat-inactivated FBS, $10 \%$ horse serum), and resuspended in $3 \mathrm{ml}$ of complete medium. Neurons were plated onto poly-ornithine $(100 \mu \mathrm{g} / \mathrm{ml})$-coated 24 -well culture plates (Nunc, Wiesbaden, Germany) at a density of $\sim 1 \times 10^{4}$ cells/drop and incubated at $37^{\circ} \mathrm{C}$ in $5 \% \mathrm{CO}_{2}$. The following day, transient transfection experiments were performed using FuGene-6 (Roche Applied Science) as described by the manufacturer. eGFP expression was checked $24 \mathrm{~h}, 48 \mathrm{~h}$ and $72 \mathrm{~h}$ after transfection and the cells were fixed for immunocytochemistry analysis or lysed for luciferase $/ \beta$-galactosidase activity ratio determination 48 hours after transfection.

\section{Immunocytochemistry (ICC) and Immunohistochemistry (IHC)}

Glass coverslips were washed in nitric acid (65\%) for 1-2 days, rinsed in water for 2-3 hours, then in ethanol 100\% for $2 \mathrm{~h}$, air-dried and sterilized by autoclaving. Cells were washed in TBS (Tris-Buffered Saline), fixed for $20 \mathrm{~min}$ in $4 \%$ PFA (paraformaldehyde) at $4^{\circ} \mathrm{C}$, washed in TBS and permeabilized/blocked for minimum $1 \mathrm{~h}$ in blocking buffer (TBS, $1 \%$ BSA, $0.2 \%$ teleostean gelatin, $0.1 \%$ Triton$\mathrm{X} 100)$ at room temperature [5]. For Immunohistochemistry, the blocking buffer was composed of TBS, $0.25 \%$ gelatin, $0.1 \%$ Triton-X100. The same buffer without Triton X100 was used for antibody incubations and washes. Cells were incubated overnight in primary antibody solution (Table 1 ) at $4^{\circ} \mathrm{C}$ (in humid chamber), washed 3 times and incubated for $1 \mathrm{~h}$ in secondary antibody solution at room temperature (in humid chamber). The latest wash was performed in TBS before mounting in Vectashield HardSet Mounting Medium with DAPI (Vector Laboratories, Peterborough, United Kingdom).

\section{Western Blotting (WB)}

After 2 washes with PBS, cells on $10 \mathrm{~cm}^{2}$ plates were lysed by adding $300 \mu \mathrm{l}$ lysis buffer $(0.15 \mathrm{M} \mathrm{NaCl}, 0.05 \mathrm{M}$ TrisBase, $1 \%$ TritonX-100, $1 \%$ Sodium deoxycholate, $0.1 \%$ SDS) supplemented with protease inhibitor cocktail (Roche) and PMSF (phenylmethylsulfonyl fluoride). After centrifugation at $4^{\circ} \mathrm{C}$, the supernatant was removed and the protein content was determined using Bradford reagent (Bio-Rad Laboratories, Hercules, CA, USA). Samples were boiled in sample buffer $(2 \times: 4 \%$ SDS, $10 \% \beta$ mercaptoethanol, $135 \mathrm{mM}$ Tris- $\mathrm{HCl}$ pH6.8, 20\% glycerol, $1 \%$ bromophenol blue). Proteins ( $20 \mu \mathrm{g} / \mathrm{sample})$ were separated by $10 \%$ SDS-PAGE, and transferred onto PVDF (Amersham Hybond-P). Blots were blocked in TBST- 
Table 1: Antibodies used for immunohistochemistry and Western blot analysis.

\begin{tabular}{|c|c|c|c|c|c|}
\hline \multirow[t]{2}{*}{ Antibody } & \multirow[t]{2}{*}{ reference } & \multicolumn{3}{|c|}{ Dilution } & \multirow[t]{2}{*}{ Company } \\
\hline & & ICC & IHC & WB & \\
\hline Anti-Dcx(C-18) & (Goat) sc-8066 & $1 / 200$ & $1 / 500$ & $1 / 1000$ & SantaCruz Biotechnology \\
\hline Anti-Oct3/4 (C10) & (Mouse) sc-5279 & $1 / 200$ & & $1 / 200$ & SantaCruz Biotechnology \\
\hline Anti- $\beta$ III Tubulin & (Mouse) T8660 & $1 / 1000$ & & & Sigma-Aldrich \\
\hline Anti-a-Tubulin & (Mouse) T6074 & & & $1 / 25000$ & Sigma-Aldrich \\
\hline Anti-NeuN & (Mouse) MAB377 & $1 / 100$ & $1 / 500$ & & Chemicon \\
\hline \multirow[t]{2}{*}{ TRITC-conjugated } & (DAG) 705-025-147 & $1 / 500$ & $1 / 500$ & & Jackson Immuno Research \\
\hline & (DAM) 705-205-151 & $1 / 500$ & $1 / 500$ & & Jackson Immuno Research \\
\hline \multirow[t]{2}{*}{ HRP-conjugate } & (RAG) A5420 & & & $1 / 2000$ & Sigma-Aldrich \\
\hline & (MAG) A4416 & & & $1 / 2000$ & Sigma-Aldrich \\
\hline
\end{tabular}

BSA $1 \%$ and incubated overnight with the primary antibody at $4^{\circ} \mathrm{C}$. The following day, membranes were washed and then incubated $1 \mathrm{~h}$ with the secondary antibody at room temperature before washes. Detection was performed using ECL Plus method (Amersham).

\section{Plasmid Construction}

The Mus musculus Doublecortin cDNA sequence is available under GenBank Accession no. NM010025 and genomic DNA sequence available under GenBank Accession no. BX530055, (Sanger Institute, Cambridge United Kingdom).

Bacterial Colony PCR-based screening was performed on the Library clone RP23-377E2 Bacterial Artificial Chromosome (BAC) (Children's Hospital Oakland Research Institute, California), using the Elongase Enzyme Mix (Invitrogen-Gibco) and three different 5'primers ( $p d c x$ forward F1, F1.2, F2) and one 3'-primer (pdcx reverse):

$p d c x$ F 1: 5'-TTTGTCTCTCTCAGCCTCGG-3' $p d c x$ F 1.2: 5'-TTCTTAGGTGCTGCTTTCCC-3' $p d c x$ F 2: 5'-ACTGACCTCTGTTCAGTTCC-3' $p d c x$ R: 5'-GTTTTCTGCTGGTTGGGTG-3'

Each PCR product (1 kbp, $1.2 \mathrm{kbp}, 2 \mathrm{kbp}$ ) was cloned into pGEM-T easy (Promega) and subjected to DNA sequencing with T7 and SP6 oligonucleotide primers (GIGA, University of Liège, Belgium). The derived sequence was confirmed by comparison with the mouse genomic DNA obtained from $\mathrm{C} 57 \mathrm{Bl} / 6 \mathrm{~J}$ mice and available under NCBI nucleotide bank Accession no. BX530055. Different fragments were cut with Pst1, Hin$d I I I$ (for $p d c x 249 \mathrm{bp}$ ) and Apa1 restriction enzymes (New England Biolabs, Ipswich, MA, USA) and cloned into the pEGFP1 vector (BD/Clontech, Heidelberg, Germany). Integrity of the putative $D c x$ gene regulatory sequences of $D c x$ gene, $p d c x-(1 \mathrm{kbp}, 1.2 \mathrm{kbp}, 2 \mathrm{kbp})$-eGFP was con- firmed by sequencing (Génome Express, Meylan, France).

\section{(RT)-PCR}

Total RNA was extracted from cells (at day $0,4,8$ on gelatin and day 0,10 and 20 on poly-ornithine/laminin of ESC differentiation program, corresponding to DD0, DD4, DD8, DD18 and DD28 respectively) using instapure solution (Roche Applied Science, Vilvoorde, Belgium). Total RNA $(5 \mu \mathrm{g})$ was used for a reverse transcriptional reaction. PCR was then carried out in a final volume of 50 $\mu$ l containing $2.5 \mathrm{U}$ of Taq polymerase (Promega), $2 \mu \mathrm{l}$ of each selected primer and $0.2 \mu \mathrm{l}$ of Gapdh primers $(10 \mu \mathrm{M}$ each, from Eurogentec, Seraing, Belgium), $1 \mu \mathrm{l}$ of dNTP mix (10 mM each, from Promega) and $1 \mu \mathrm{l}$ of the RT product. The primers used are detailed in Table 2.

PCR products were analyzed on agarose gel (Eurogentec) and quantified using Image Master 1D Prime v3.01 program (Amersham). The results are shown as the relative amount of the mRNA of interest relative to the Gapdh housekeeping gene mRNA.

\section{Site-directed mutagenesis}

Site-directed mutagenesis of the LEF, HNF6 and NF-Y sites in the $D c x$ promoter was performed on $p d c x 249 \mathrm{bp}-$ luc plasmid. Whole plasmids carrying the mutation were obtained by performing PCR using primers listed in Table 3. Amplification reactions were carried out in $50 \mu \mathrm{l}$ total volume containing $2.5 \mathrm{U}$ of $\mathrm{Pfu}$ polymerase (Promega), 2 $\mu \mathrm{l}$ of each primer (10 $\mu \mathrm{M}$ each; Eurogentec), $1 \mu \mathrm{l}$ of dNTP mix (10 mM each; Promega) and $50 \mathrm{ng}$ DNA template (pdcx249bp-luc) and 2.5 units Pfu Ultra. The thermocycling program used was $94^{\circ} \mathrm{C}$ for $1 \mathrm{~min}$, followed by 18 cycles of $94^{\circ} \mathrm{C}$ for $1 \mathrm{~min}, 55^{\circ} \mathrm{C}$ for $1 \mathrm{~min}, 72^{\circ} \mathrm{C}$ for $10 \mathrm{~min}$ and a final extension cycle of $72^{\circ} \mathrm{C}$ for $10 \mathrm{~min}$. The template was degraded using 10 units of DpnI restriction endonuclease at $37^{\circ} \mathrm{C}$ for at least $2 \mathrm{~h}$. After transforma- 
Table 2: Primers used for PCR.

\begin{tabular}{|c|c|c|c|c|}
\hline Gene & Sense primer (3' - 5') & Antisense primer (3' - 5') & $\operatorname{Tm}\left({ }^{\circ} \mathrm{C}\right)$ & Ref \\
\hline$D c x$ & AAGTGACCAACAAGGCTATT & TCATTGTGTITCTCCCGGA & 60 & [54] \\
\hline Lef & GAACGAGTCTGAAATCATCC & GTAGGGATATCAGGAGCTGG & 53 & [55] \\
\hline Tcf1 & САTTCCTGGAGTCCTGAAGC & CCTGTCAGTTACACCAACG & 57 & / \\
\hline Tcf3 & AGGAAATCACCAGTCACCGT & GTACTTGGCCTGTTCTTCTC & 55 & [56] \\
\hline Tcf4 & TTCAAAGACGACGGCGAACAG & TTGCTGTACGTGATAAGAGGCG & 55 & [56] \\
\hline Hnf6 & TTCCAGCGCATGTCGGCGCTC & GGTACTAGTCCGTGGTTCTTC & 55 & [57] \\
\hline Oc2 & ATGCCGGTCTCAGGGGACTCTC & GGCGAAGAGTGTTCGGCGTTGGAG & 55 & [58] \\
\hline$N f-y a$ & CTGGAGCCTCTGATTGGGT & CTCTACAGATCCCAGGCAGC & 55 & [59] \\
\hline$N f-y b$ & AGGATCCACCACCTTITTGA & TAGCTGGGAGGCATCTGTG & 55 & [59] \\
\hline$N f-y c$ & TTTCTTCCATGACTCTGGGC & GCTGCTTTCTTCGCTGGA & 55 & [59] \\
\hline Gapdh & ACCACAGTCCATGCCATCAC & TCCACCACCCTGTTGCTGTA & & \\
\hline
\end{tabular}

All sequences were designed using the PRIMER 3 software http://frodo.wi.mit.edu/primer3/input.htm.

tion of competent E. coli, recombinant plasmids were isolated and their sequence verified.

\section{Ex vivo electroporation}

Plasmids were prepared using the EndoFree Plasmid Kit (Qiagen, Hilden, Germany). E14.5 pregnant mice were anesthetized by gas and euthanized by cervical dislocation. The embryonic chain was removed from the mother, the embryos were isolated from the amniotic sac and decapitated. DNA was microinjected into lateral ventricles of isolated embryonic mouse heads placed in icecold L-15 medium supplemented with $3 \%$ glucose $(1 \mathrm{M})$, $2.6 \%$ sodium bicarbonate $(1 \mathrm{M})$ and $1 \%$ penicillin/streptomycin $(100 \times)$. For DNA microinjection (using the FemtoJet apparatus, Eppendorf AG, Hamburg, Germany), 75$\mathrm{mm}$ glass capillary tubes were pulled and tips were broken. Plasmid solutions were stained with Fast Green solution $(0.05 \%)$ to monitor injection sites. Electroporations were performed on whole heads (skin and skull intact) using an ECM 830 electroporator (BTX) and the follow- ing parameters: five $50 \mathrm{~ms}$ long pulses separated by $1 \mathrm{~s}$ long intervals at $50 \mathrm{~V}$. After pulse delivery, the embryo heads were immersed in ice-cold L-15 supplemented with $3 \%$ glucose $(1 \mathrm{M}), 2.6 \%$ sodium bicarbonate $(1 \mathrm{M})$ and $1 \%$ penicillin/streptomycin, brains were extracted and transferred into liquid $3 \%$ low melting agarose $\left(37^{\circ} \mathrm{C}\right.$; Bio-Rad Laboratories, Hercules, CA, USA) and incubated on ice for $1 \mathrm{~h}$. Embedded brains were cut coronally (250 $\mu \mathrm{m}$ ) with a vibratome (VT1000S, Leica). Brain slices were transferred and maintained in organotypic slice cultures on sterilized culture plate inserts $(0.4-\mu \mathrm{m}$ pore size; Millicell-CM, Millipore Billerica, MA, USA). Brain slices were maintained in semi-dry conditions in wells containing Neurobasal medium supplemented with $2 \%$ B27, $1 \%$ N2, $1 \%$ penicillin/streptomycin. After 2 or 3 days, slices were fixed for $30 \mathrm{~min}$ in $4 \%$ PFA at $4^{\circ} \mathrm{C}$ and incubated overnight in sucrose solution (20\%). The following day, slices were sectioned using a cryostat at 14 micron-thickness (LEICA CM3050S) and stained for immunofluorescence as previously described.

Table 3: Primers used for site-directed mutagenesis.

\begin{tabular}{|c|c|c|c|}
\hline Mutated site & Primer (5'- 3') & Sequence & Ref \\
\hline \multirow[t]{2}{*}{ pdcxLef* } & Sense & ATCTCTCTATGCCGTGTITGTCTGAGCTCCAAGC & {$[60]$} \\
\hline & Antisense & GCTTGGAGCTCAGACAAACACGGCATAGAGAGAT & \\
\hline \multirow[t]{2}{*}{ pdcxHnf6* } & Sense & AGGCATAGAGAGCGTITGTICTITTCTCAGCATCTCCACCCAACC & / \\
\hline & Antisense & GGTTGGGTGGAGATGCTGAGAGAAAGAAACAAACGCTCTCTATGCCT & \\
\hline \multirow[t]{2}{*}{ pdcxNf-y ${ }_{1}^{*}$} & Sense & AGGCATAGAGAGCGGTIITTCTITCTCTCAGCTCTCCACCC & {$[61]$} \\
\hline & Antisense & GGGTGGAGAGCTGAGAGAAAGAAAAAACCGCTCTCTAGCCT & \\
\hline \multirow[t]{2}{*}{$p d c x N f-y_{2}^{*}$} & Sense & CGTTGTTTCTGCTGGTITTGGGTGGAGATGC & {$[61]$} \\
\hline & Antisense & GCATCTCCACCCAAAACCAGCAGAAACAACG & \\
\hline
\end{tabular}

PCR fragments carrying the mutation are obtained by annealing the following primers in the pdcx249bp-Luc plasmid. 


\section{Statistical analysis}

Statistical analyses were performed by one-way ANOVA followed by Dunnett's post hoc tests, using a GraphPad Prism program (GraphPad, San Diego, CA, USA). Each experiment was performed in triplicates and repeated on at least three different occasions. Individual comparisons are expressed as mean \pm SD.

\section{Additional material}

\section{Additional file 1 Putative binding sites found in Dcx regulatory}

sequence of $\mathbf{2} \mathbf{~ k b}$. These putative binding sites were detected using Matinspector software http://www.genomatix.de.

Additional file $\mathbf{2}$ Simultaneous mutation of the LEF, HNF6 and NF-Y binding sites in Dcx promoter. ESR1 cells were transfected with the indicated constructs at day of differentiation 0 (DD0) and luciferase activity relative to $\beta$-galactosidase activity was determined 48 hours later. The different constructs were $p d c \times 249 \mathrm{bp}$-Luc, 79bp-deleted pdcx249bp-Luc construct ( $p d c \times 249 \mathrm{bp}-$-Luc) and $p d c \times 249 \mathrm{bp}$-Luc with mutated binding site (pdcx249bp/Lef*, pdcx249bp/Hnf6* ${ }^{*}$ pdcx249bp/Nf-y2*, $p d c \times 249 \mathrm{bp} / \mathrm{Nf}-\mathrm{y} 3^{*}$ and $p d c \times 249 \mathrm{bp} /$ Lef*/Hnf6*/Nf-y2*) and the promoterless control (CTL). The activity of each construct is expressed relative to that of the pdcx249bp-Luc construct, set arbitrarily to 1. Each value represents the mean \pm SD of one transfection experiment, performed in triplicate. Asterisks mean significantly different from $p d c \times 249 \mathrm{bp}$ values at $P<0.05\left(^{*}\right)$ or $P<0.01\left(^{* *}\right)$.

\section{Abbreviations}

Dcx: Doublecortin; CGN: Cerebellar Granule Neurons; DD: Day of Differentiation; BMP4: Bone Morphogenic Protein-4; GFAP: Glial fibrillary acidic protein LIF: Leukemia Inhibitory Factor; MAP: Microtubule-Associated Protein; mESC: mouse Embryonic Stem Cells; PND: Post Natal Day; LEF1: Lymphoid enhancer factor-1; HNF6: Hepatocyte Nuclear Factor-6; OC2: Onecut-2; NF-Y: Nuclear Factor-Y

\section{Authors' contributions}

MP carried out the study design, plasmid constructions, cell cultures, transfections, western blotting, Immunocytochemistry, ex-vivo electroporation, data analysis and drafted the manuscript. MM participated in the study design, sequence homologies and manuscript writing. MB performed the confocal immunofluorescence study and PCR experiments. GB performed the $p d c \times 1 \mathrm{~kb}$ eGFP and $p d c x 1 \mathrm{~kb}$-eGFP constructions. JCP participated in the study design and coordination and helped to draft the manuscript. All authors read and approved the final manuscript.

\section{Acknowledgements}

This work was supported by grants of the F.N.R.S. (JCP), the EEC (Marie Curie IRG) (JCP). M. Piens is a recipient of a F.R.I.A. PhD studentship. M. Muller is a "Chercheur Qualifié du FNRS". We thank L. de Nijs (GIGA-Neurosciences, Université de Liège) for technical help to perform ex vivo electroporation experiments. We also thank Dr B. Rogister (GIGA-Neurosciences, Université de Liège) for his advices and suggestions and Dr A. Nagy (Mount Sinai Hospital, Toronto, Canada) and Dr D. Pirottin (Animal Genomic Unit-GIGA-R, Université de Liège) for providing ESR1 cells.

\section{Author Details}

'Laboratory for Animal Physiology, Université de Liège, B-4000 Liège, SartTilman, Belgium, ${ }^{2}$ Laboratory for Molecular Biology and Genetic Engineering GIGA-R, Université de Liège, B-4000 Liège, Sart-Tilman, Belgium and ${ }^{3}$ GIGANeurosciences, Université de Liège, B-4000 Liège, Sart-Tilman, Belgium

Received: 2 October 2009 Accepted: 28 May 2010

Published: 28 May 2010

\section{References}

1. Francis F, Koulakoff A, Boucher D, Chafey P, Schaar B, Vinet MC, Friocourt G, McDonnell N, Reiner O, Kahn A, et al:: Doublecortin is a developmentally regulated, microtubule-associated protein expressed in migrating and differentiating neurons. Neuron 1999, 23(2):247-256.

2. des Portes V, Pinard JM, Billuart P, Vinet MC, Koulakoff A, Carrié A, Gelot A, Dupuis E, Motte J, Berwald-Netter Y, et al:: A novel CNS gene required for neuronal migration and involved in X-linked subcortical laminar heterotopia and lissencephaly syndrome. Cell 1998, 92(1):51-61.

3. Walker TL, Yasuda T, Adams DJ, Bartlett PF: The doublecortin-expressing population in the developing and adult brain contains multipotential precursors in addition to neuronal-lineage cells. Journal of Neuroscience 2007, 27(14):3734-3742.

4. Friocourt G, Koulakoff A, Chafey P, Boucher D, Fauchereau F, Chelly J, Francis F: Doublecortin functions at the extremities of growing neuronal processes. Cereb Cortex 2003, 13(6):620-626.

5. Brown JP, Couillard-Després S, Cooper-Kuhn CM, Winkler J, Aigner L, Kuhn HG: Transient expression of doublecortin during adult neurogenesis. J Comp Neuro/ 2003, 467(1):1-10.

6. Mattar P, Britz O, Johannes C, Nieto M, Ma L, Rebeyka A, Klenin N, Polleux $F$, Guillemot F, Schuurmans C: A screen for downstream effectors of Neurogenin2 in the embryonic neocortex. Developmental Biology 2004, 273(2):373-389.

7. Couillard-Despres S, Winner B, Schaubeck S, Aigner R, Vroemen M, Weidner N, Bogdahn U, Winkler J, Kuhn H, Aigner L: Doublecortin expression levels in adult brain reflect neurogenesis. Eur J Neurosci 2005, 21(1):1-14.

8. Gleeson JG, Allen KM, Fox JW, Lamperti ED, Berkovic S, Scheffer I, Cooper EC, Dobyns WB, Minnerath SR, Ross ME, et al:: Doublecortin, a brainspecific gene mutated in human X-linked lissencephaly and double cortex syndrome, encodes a putative signaling protein. Cell 1998, 92(1):63-72.

9. Corbo JC, Deuel TA, Long JM, LaPorte P, Tsai E, Wynshaw-Boris A, Walsh C: Doublecortin is required in mice for lamination of the hippocampus but not the neocortex. Journal of Neuroscience 2002, 22(17):7548-7557.

10. Ramos R: Heterotopia Formation in Rat but Not Mouse Neocortex after RNA Interference Knockdown of DCX. Cerebral Cortex 2005, 16(9):1323-1331.

11. Bai J, Ramos R, Ackman J, Thomas A, Lee R, Loturco J: RNAi reveals doublecortin is required for radial migration in rat neocortex. Nat Neurosci 2003, 6(12):1277-1283.

12. Loturco J, Bai J: The multipolar stage and disruptions in neuronal migration. Trends in Neurosciences 2006, 29(7):407-413

13. Friocourt G, Liu JS, Antypa M, Rakic S, Walsh C, Parnavelas JG: Both doublecortin and doublecortin-like kinase play a role in cortical interneuron migration. Journal of Neuroscience 2007, 27(14):3875-3883.

14. Deuel TA, Liu JS, Corbo JC, Yoo SY, Rorke-Adams LB, Walsh C: Genetic interactions between doublecortin and doublecortin-like kinase in neuronal migration and axon outgrowth. Neuron 2006, 49(1):41-53.

15. Zhou Q, Anderson DJ: The bHLH transcription factors OLIG2 and OLIG1 couple neuronal and glial subtype specification. Cell 2002, 109(1):61-73.

16. Paratore C, Hagedorn L, Floris J, Hari L, Kléber M, Suter U, Sommer L: Cellintrinsic and cell-extrinsic cues regulating lineage decisions in multipotent neural crest-derived progenitor cells. Int J Dev Biol 2002, 46(1):193-200.

17. Kintner C: Neurogenesis in embryos and in adult neural stem cells. J Neurosci 2002, 22(3):639-643.

18. Gleeson JG, Lin PT, Flanagan LA, Walsh CA: Doublecortin is a microtubule-associated protein and is expressed widely by migrating neurons. Neuron 1999, 23(2):257-271.

19. Nadarajah B, Alifragis $P$, Wong RO, Parnavelas JG: Neuronal migration in the developing cerebral cortex: observations based on real-time imaging. Cereb Cortex 2003, 13(6):607-611.

20. Bibel M, Richter J, Schrenk K, Tucker K, Staiger V, Korte M, Goetz M, Barde Y: Differentiation of mouse embryonic stem cells into a defined neuronal lineage. Nat Neurosci 2004, 7(9):1003-1009.

21. Zhang JQ, Yu XB, Ma BF, Yu WH, Zhang AX, Huang G, Mao FF, Zhang XM, Wang ZC, Li SN, et al:: Neural differentiation of embryonic stem cells induced by conditioned medium from neural stem cell. Neuroreport 2006, 17(10):981-986.

22. Billon N, Jolicoeur C, Tokumoto Y, Vennström B, Raff M: Normal timing of oligodendrocyte development depends on thyroid hormone receptor alpha 1 (TRalpha1). EMBO J 2002, 21(23):6452-6460. 
23. Lemaigre F: [Structure, function and physiopathological implications of HNF-6, a prototype of a new family of gene expression regulators]. Bull Mem Acad RMed Belg 1999, 154(6 Pt 2):295-301.

24. Landry C, Clotman F, Hioki T, Oda H, Picard JJ, Lemaigre FP, Rousseau GG: HNF- 6 is expressed in endoderm derivatives and nervous system of the mouse embryo and participates to the cross-regulatory network of liver-enriched transcription factors. Developmental Biology 1997 192(2):247-257

25. Jacquemin P, Lannoy VJ, Rousseau GG, Lemaigre FP: OC-2, a novel mammalian member of the ONECUT class of homeodomain transcription factors whose function in liver partially overlaps with that of hepatocyte nuclear factor-6. J Biol Chem 1999, 274(5):2665-2671.

26. Willems E, Mateizel I, Kemp C, Cauffman G, Sermon K, Leyns L: Selection of reference genes in mouse embryos and in differentiating human and mouse ES cells. Int J Dev Biol 2006, 50(7):627-635.

27. Reyes JH, O'Shea KS, Wys NL, Velkey JM, Prieskorn DM, Wesolowski K, Miller JM, Altschuler RA: Glutamatergic neuronal differentiation of mouse embryonic stem cells after transient expression of neurogenin 1 and treatment with BDNF and GDNF: in vitro and in vivo studies. $J$ Neurosci 2008, 28(48):12622-12631.

28. Abranches E, Silva M, Pradier L, Schulz H, Hummel O, Henrique D, Bekman E: Neural differentiation of embryonic stem cells in vitro: a road map to neurogenesis in the embryo. PLOS ONE 2009, 4(7):e6286

29. Pereira L, Yi F, Merrill BJ: Repression of Nanog gene transcription by Tcf3 limits embryonic stem cell self-renewal. Mol Cell Biol 2006, 26(20):7479-7491.

30. Tóth G, Gáspári Z, Jurka J: Microsatellites in different eukaryotic genomes: survey and analysis. Genome Res 2000, 10(7):967-981.

31. Katti MV, Ranjekar PK, Gupta VS: Differential distribution of simple sequence repeats in eukaryotic genome sequences. Mol Biol Evol 2001, 18(7):1161-1167.

32. Huang T-S, Lee C-C, Chang A-C, Lin S, Chao C-C, Jou Y-S, Chu Y-W, Wu CW. Whang-Peng J: Shortening of microsatellite $\operatorname{deoxy}(\mathrm{CA})$ repeats involved in GL331-induced down-regulation of matrix metalloproteinase-9 gene expression. Biochem Biophys Res Commun 2003, 300(4):901-907.

33. Gebhardt F, Zänker KS, Brandt B: Modulation of epidermal growth factor receptor gene transcription by a polymorphic dinucleotide repeat in intron 1. J Biol Chem 1999, 274(19):13176-13180

34. Meyer G, Perez-Garcia CG, Gleeson J: Selective expression of doublecortin and LIS1 in developing human cortex suggests unique modes of neuronal movement. Cereb Cortex 2002, 12(12):1225-1236.

35. Ying Q, Stavridis M, Griffiths D, Li M, Smith A: Conversion of embryonic stem cells into neuroectodermal precursors in adherent monoculture. Nat Biotech 2003, 21(2):183-186.

36. Flanagan LA, Rebaza LM, Derzic S, Schwartz PH, Monuki ES: Regulation of human neural precursor cells by laminin and integrins. J Neurosci Res 2006, 83(5):845-856.

37. De Arcangelis A, Georges-Labouesse E: Integrin and ECM functions: roles in vertebrate development. Trends Genet 2000, 16(9):389-395.

38. Andressen C, Adrian S, Fässler R, Arnhold S, Addicks K: The contribution of beta1 integrins to neuronal migration and differentiation depends on extracellular matrix molecules. Eur J Cell Bio/ 2005, 84(12):973-982.

39. Hannan AJ, Henke RC, Seeto GS, Capes-Davis A, Dunn J, Jeffrey PL: Expression of doublecortin correlates with neuronal migration and pattern formation in diverse regions of the developing chick brain. $J$ Neurosci Res 1999, 55(5):650-657.

40. Lee SH, Kim YJ, Lee KM, Ryu S, Yoon BW: Ischemic preconditioning enhances neurogenesis in the subventricular zone. Neuroscience 2007, 146(3):1020-1031

41. Karl C, Couillard-Despres S, Prang P, Munding M, Kilb W, Brigadski T, Plotz $\mathrm{S}$, Mages W, Luhmann H, Winkler J, et al:: Neuronal precursor-specific activity of a human doublecortin regulatory sequence. $J$ Neurochem 2005, 92(2):264-282

42. Tang K, Yang J, Gao X, Wang C, Liu L, Kitani H, Atsumi T, Jing N: Wnt-1 promotes neuronal differentiation and inhibits gliogenesis in P19 cells. Biochemical and Biophysical Research Communications 2002, 293(1):167-173

43. Korinek V, Barker N, Willert K, Molenaar M, Roose J, Wagenaar G, Markman M, Lamers W, Destree O, Clevers H: Two members of the Tcf family implicated in Wnt/beta-catenin signaling during embryogenesis in the mouse. Mol Cell Biol 1998, 18(3):1248-1256.
44. Katoh M: Regulation of WNT signaling molecules by retinoic acid during neuronal differentiation in NT2 cells: threshold model of WNT action (review). Int J Mol Med 2002, 10(6):683-687.

45. Haegele L, Ingold B, Naumann H, Tabatabai G, Ledermann B, Brandner S: Wnt signalling inhibits neural differentiation of embryonic stem cells by controlling bone morphogenetic protein expression. Mol Cell Neurosci 2003, 24(3):696-708.

46. Czyz J, Wobus A: Embryonic stem cell differentiation: the role of extracellular factors. Differentiation 2001, 68(4-5):167-174.

47. Kielman MF, Rindapää M, Gaspar C, van Poppel N, Breukel C, van Leeuwen S, Taketo MM, Roberts S, Smits R, Fodde R: Apc modulates embryonic stem-cell differentiation by controlling the dosage of beta-catenin signaling. Nat Genet 2002, 32(4):594-605.

48. Hirabayashi Y: The Wnt/-catenin pathway directs neuronal differentiation of cortical neural precursor cells. Development 2004, 131(12):2791-2801.

49. Viti J, Gulacsi A, Lillien $L$ : Wnt regulation of progenitor maturation in the cortex depends on Shh or fibroblast growth factor 2. Journal of Neuroscience 2003, 23(13):5919-5927.

50. Hong SK, Kim CH, Yoo KW, Kim HS, Kudoh T, Dawid IB, Huh TL: Isolation and expression of a novel neuron-specific onecut homeobox gene in zebrafish. Mech Dev 2002, 112(1-2):199-202.

51. Sasakura Y, Makabe KW: A gene encoding a new ONECUT class homeodomain protein in the ascidian Halocynthia roretzi functions in the differentiation and specification of neural cells in ascidian embryogenesis. Mech Dev 2001, 104(1-2):37-48,

52. Nguyen DN, Rohrbaugh M, Lai Z: The Drosophila homolog of Onecut homeodomain proteins is a neural-specific transcriptional activator with a potential role in regulating neural differentiation. Mech Dev 2000, 97(1-2):57-72

53. Bibel M, Richter J, Schrenk K, Tucker K, Staiger V, Korte M, Goetz M, Barde Y: Differentiation of mouse embryonic stem cells into a defined neuronal lineage. Nat Neurosci 2004, 7(9):1003-1009.

54. Matsuo N, Kawamoto S, Matsubara K, Okubo K: Cloning and developmental expression of the murine homolog of doublecortin. Biochemical and Biophysical Research Communications 1998, 252(3):571-576

55. Howe D, Bromidge T: Variation of LEF-1 mRNA expression in low-grade B-cell non-Hodgkin's lymphoma. Leuk Res 2006, 30(1):29-32.

56. Murakami T, Toda S, Fujimoto M, Ohtsuki M, Byers HR, Etoh T, Nakagawa H: Constitutive activation of Wnt/beta-catenin signaling pathway in migration-active melanoma cells: role of LEF-1 in melanoma with increased metastatic potential. Biochemical and Biophysical Research Communications 2001, 288(1):8-15

57. Pierreux CE, Vanhorenbeeck V, Jacquemin P, Lemaigre FP, Rousseau GG: The transcription factor hepatocyte nuclear factor-6/Onecut-1 controls the expression of its paralog Onecut-3 in developing mouse endoderm. J Biol Chem 2004, 279(49):51298-51304.

58. Jacquemin P, Pierreux CE, Fierens S, van Eyll JM, Lemaigre FP, Rousseau GG: Cloning and embryonic expression pattern of the mouse Onecut transcription factor OC-2. Gene Expr Patterns 2003, 3(5):639-644.

59. Tomita T, Kimura S: Regulation of mouse Scgb3a1 gene expression by NF-Y and association of $\mathrm{CpG}$ methylation with its tissue-specific expression. BMC Mol Biol 2008, 9:5.

60. Li B, Mackay DR, Dai Q, Li TW, Nair M, Fallahi M, Schonbaum CP, Fantes J, Mahowald AP, Waterman ML, et al.: The LEF1/beta -catenin complex activates movo1, a mouse homolog of Drosophila ovo required for epidermal appendage differentiation. Proc Natl Acad Sci USA 2002, 99(9):6064-6069.

61. Desaint S, Hansmannel F, Clémencet MC, Le Jossic-Corcos C, NicolasFrances V, Latruffe N, Cherkaoui-Malki M: NFY interacts with the promoter region of two genes involved in the rat peroxisomal fatty acid beta-oxidation: the multifunctional protein type 1 and the 3ketoacyl-CoA B thiolase. Lipids in health and disease 2004, 3:4.

doi: $10.1186 / 1471-2202-11-64$

Cite this article as: Piens et al., A short upstream promoter region mediates transcriptional regulation of the mouse doublecortin gene in differentiating neurons BMC Neuroscience 2010, 11:64 